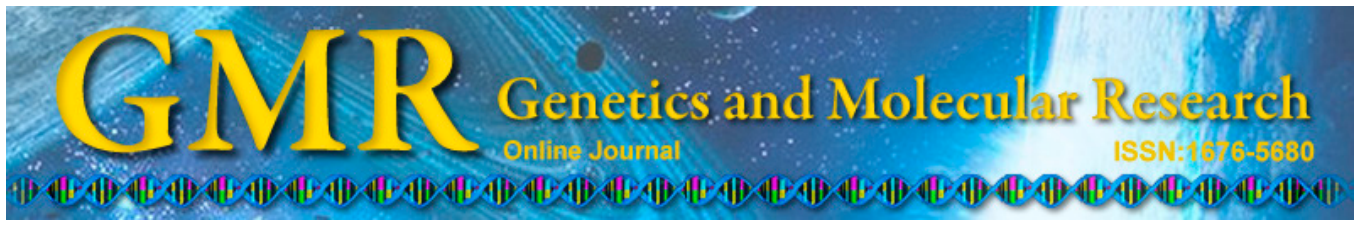

\title{
Karyotype of Rhodnius montenegrensis (Hemiptera, Triatominae)
}

\author{
K.C.C. Alevi' ${ }^{1}$ A. Ravazi ${ }^{1}$, V.J. Mendonça ${ }^{2}$, J.A. Rosa ${ }^{2}$ \\ and M.T.V. Azeredo-Oliveira ${ }^{1}$ \\ ${ }^{1}$ Laboratório de Biologia Celular, Departamento de Biologia, \\ Instituto de Biociências, Letras e Ciências Exatas, Universidade Estadual \\ Paulista “Júlio de Mesquita Filho", São José do Rio Preto, SP, Brasil \\ ${ }^{2}$ Laboratório de Parasitologia, Departamento de Ciências Biológicas, \\ Faculdade de Ciências Farmacêuticas, \\ Universidade Estadual Paulista "Júlio de Mesquita Filho", Araraquara, SP, \\ Brasil
}

Corresponding author: K.C.C. Alevi

E-mail: kaiochaboli@hotmail.com

Genet. Mol. Res. 14 (1): 222-226 (2015)

Received April 22, 2014

Accepted October 17, 2014

Published January 16, 2015

DOI http://dx.doi.org/10.4238/2015.January.16.5

\begin{abstract}
The Triatominae subfamily comprises 6 tribes. The tribe Rhodniini comprises 2 genera and 22 nominal species. Rhodnius montenegrensis (Hemiptera, Triatominae) was recently described as evolutionarily related to $R$. robustus. Therefore, in order to contribute to karyosystematic study of the tribe Rhodniini, this report describes the number of chromosomes and compares the karyotype of $R$. montenegrensis to that of all other species in the tribe, in order to determine the karyotypic evolution of the tribe Rhodniini. The seminiferous tubules of adult males, after being removed and fixated on a cover slip, were processed with lactoaceto-orcein for cytogenetic analysis. R. montenegrensis, as well as all other species of the tribe Rhodniini showed 22 chromosomes (20 autosomes $+\mathrm{XY}$ ). Thus, we hereby describe the karyotype of the species $R$. montenegrensis and mainly highlight that the
\end{abstract}


tribe Rhodniini displays karyotypic homogeneity, demonstrating itself as a derived group to a lesser extent when compared to the number of chromosomes of the common ancestors of the subfamily Triatominae.

Key words: Tribe Rhodniini; Cytotaxonomy; Karyosystematic

\section{INTRODUCTION}

Triatomines are insects taxonomically included in the Order Hemiptera and Suborder Heteroptera, within the Family Reduviidae, and subfamily Triatominae (Lent and Wygodzinsky, 1979). The subfamily Triatominae consists of 148 species (Abad-Franch et al., 2013; Alevi et al., 2013d; Jurberg et al., 2013; Poinar, 2013). All triatomine species are susceptible to infection by the protozoan Trypanosoma cruzi (Kinetoplastida, Trypanosomatidae) and therefore potential vectors of Chagas disease. Infection occurs through food with infected blood and all instars that are likely to ingest the parasite, since hematophagy is mandatory at all stages of the insect's lifecycle (Noireau et al., 2009).

The subfamily Triatominae comprises 6 tribes, namely, Alberproseniini, Bolboderini, Cavernicolini, Linshcosteusinii, Rhodniini, and Triatomini (Galvão et al., 2003; Tartarotti et al., 2006; Alevi et al., 2013d). The tribe Rhodniini comprises of 2 genera and 22 nominal species (Table 1). Recently, da Rosa et al. $(2012,2014)$ described the species Rhodnius montenegrensis as related to $R$. robustus that belongs to $R$. prolixus complex. This species was found to be infected by the protozoan Trypanosoma rangeli (Meneguetti et al., 2014).

Table 1. Species of triatomines that constitute the tribe Rhodniini with their respectives karyotypes.

\begin{tabular}{|c|c|c|}
\hline Tribe Rhodniini & Karyotype & Described by \\
\hline P. arthuri & Not described & \\
\hline P. coreodes & $2 n=20 A+X Y$ & Schreiber and Pellegrino (1950) \\
\hline P. tertius & $2 n=20 A+X Y$ & Panzera et al. (1998) \\
\hline R. amazonicus & Not described & \\
\hline R. barretti & Not described & \\
\hline R. brethesi & $2 n=20 A+X Y$ & Panzera et al. (1998) \\
\hline R. colombiensis & $2 n=20 A+X Y$ & Dujardin et al. (2002) \\
\hline R. dalessandroi & Not described & \\
\hline R. domesticus & $2 n=20 A+X Y$ & Dujardin et al. (2002) \\
\hline R. ecuadoriensis & $2 n=20 A+X Y$ & Panzera et al. (1996) \\
\hline R. milesi & $2 n=20 A+X Y$ & Panzera et al. (2010) \\
\hline R. montenegrensis & $2 n=20 A+X Y$ & First described \\
\hline R. nasutus & $2 n=20 A+X Y$ & Pérez et al. (1992) \\
\hline R. neglectus & $2 n=20 A+X Y$ & Barth (1956) \\
\hline R. neivai & $2 n=20 A+X Y$ & Koshy (1979) \\
\hline R. pallescens & $2 n=20 A+X Y$ & Panzera et al. (1996) \\
\hline$R$. paraensis & Not described & \\
\hline$R$. pictipes & $2 n=20 A+X Y$ & Koshy (1979) \\
\hline$R$. prolixus & $2 n=20 A+X Y$ & Schreiber and Pellegrino (1950) \\
\hline R. robustus & $2 n=20 A+X Y$ & Koshy (1979) \\
\hline R. stali & $2 n=20 A+X Y$ & Dujardin et al. (2002) \\
\hline R. zeledoni & Not described & \\
\hline
\end{tabular}

Therefore, in order to contribute to karyosystematic study of the tribe Rhodniini, this study describes the number of chromosomes and compares the karyotype of the species $R$. 
montenegrensis with all other species of the tribe, in order to determine karyotypic evolution in the tribe Rhodniini.

\section{MATERIAL AND METHODS}

In this study, we used 10 males of the species $R$. montenegrensis, assigned by the "Triatominae Insectarium" at the Departamento de Ciências Biológicas, Faculdade de Ciências Farmacêuticas, Araraquara campus. The seminiferous tubules of adult males, after being removed and fixated on a cover slip, were processed for cytogenetic analysis using lacto-acetic orcein technique (De Vaio et al., 1985, with modifications described by Alevi et al., 2012a). The biological material was analyzed using Jenaval light microscope (Zeiss) coupled to a digital camera and an image analyzer Axio Vision LE 4.8 (Copyright ${ }^{\circ}$ 2006-2009 Carl Zeiss Imaging Solutions $\mathrm{GmbH}$ ). The images were magnified by a factor of 1000 .

\section{RESULTS}

Analysis of metaphase I (Figure 1A) and metaphase II (Figure 1B) revealed that the species $R$. montenegrensis possesses a diploid chromosome set $2 \mathrm{n}=22(20 \mathrm{~A}+\mathrm{XY})$. This chromosome number is shared across all members of the tribe Rhodniini (Table 1).
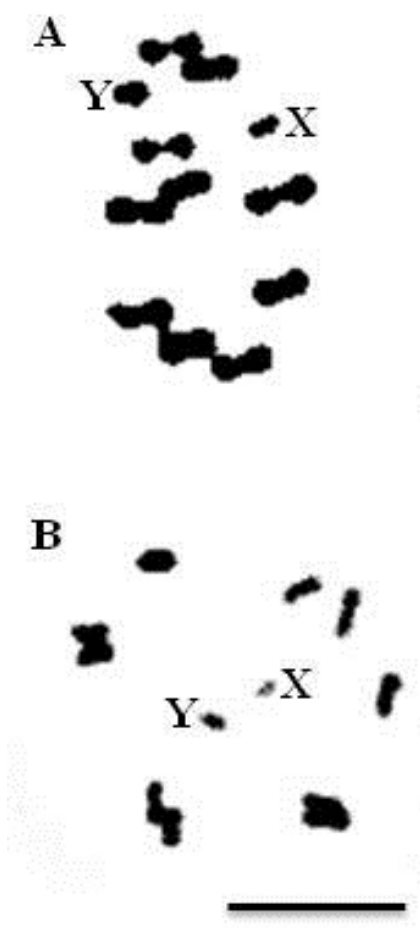

Figure 1. Seminiferous tubule of Rhodnius montenegrensis stained by lacto-aceto-orcein. A. Metaphase I with 10 bivalent autosomes and sex chromosomes. B. Metaphase II with 10 autosomes and sex chromosomes. $\mathrm{X}=\mathrm{X}$ sex chromosome; $\mathrm{Y}=\mathrm{Y}$ sex chromosome. Bar: $10 \mu \mathrm{m}$. 


\section{DISCUSSION}

The similarity between Rhodnius species is so great that one species is frequently mistaken for another, due to morphologic similarity. The classification of Rhodniini, as a monophyletic tribe, takes into account characteristics of the genus Rhodnius not shared with other triatomines, such as, apical antenna insertion, body forms, post-ocular callosities, male genital characteristics, egg-surface architecture, and presence of nitrophorin in the salivary glands. Besides these characteristics, the genera Rhodnius and Psammolestes are primarily arboreal species in contrast to the terrestrial habits of most of the other triatomines (Schofield and Dujardin, 1999).

Using DNA sequence analysis of mitochondrial ribosomal RNA, mitochondrial cytochrome b, and nuclear RNA, Monteiro et al. (2000) indicated a paraphyletic nature of the genus Rhodnius, supporting the monophyly of the Rhodniini tribe. The Rhodniini, Cavernicolini, Bolboderini, Linshcosteini, and Alberproseniini tribes constitute monophyletic groups, while the Triatomini tribe is considered polyphyletic (Tartarotti et al., 2006). No reports are currently available regarding the number of chromosomes of representatives from Alberproseniini, Cavernicolini, Bolboderini, or Linshcosteini tribes.

Cytogenetic studies have focused mainly on Rhodniini and Triatomini tribes, where 86 karyotypes have been described to date (Alevi et al., 2013d). Cytogenetic data are important tools that assist with taxonomic and evolutionary knowledge of the triatomine bugs (Ueshima, 1966; Pérez et al., 1992; Alevi et al., 2012a,b, 2013a,b,c,d, 2014).

All species of the tribe Rhodniini with the karyotype described, including $R$. montenegrensis, had the same number of chromosomes, namely $22(20$ autosomes $+\mathrm{XY})$. Besides the number of chromosomes, insects of the tribe Rhodniini share the location of the probe $45 \mathrm{~S}$ of nucleolar organizing region (NOR) which is restricted to sex chromosomes (Pita et al., 2013). Ueshima (1966) indicated that the common ancestor of all organisms of the Triatominae subfamily presents the karyotype $2 \mathrm{n}=20 \mathrm{~A}+\mathrm{XY}$, as observed in the tribe Rhodniini. The tribe Triatomini is the most derivative, since all mechanisms of sex determination, derived from fragmentation of the sex chromosome $\mathrm{X}$, are found in this group $\left(\mathrm{XY}, \mathrm{X}_{1} \mathrm{X}_{2} \mathrm{Y}, \mathrm{X}_{1} \mathrm{X}_{2} \mathrm{X}_{3} \mathrm{Y}\right)$ (Alevi et al., 2013d).

Thus, we describe the karyotype of the species R. montenegrensis and highlight that the tribe possesses karyotypic homogeneity, demonstrating itself as a derived group to a lesser extent when compared to the number of chromosomes of the common ancestors of the subfamily Triatominae.

\section{ACKNOWLEDGMENTS}

Research supported by Fundação de Amparo à Pesquisa do Estado de São Paulo (FAPESP) (Process \#2013/19764-0) and Conselho Nacional de Desenvolvimento Científico e Tecnológico (CNPq).

\section{REFERENCES}

Abad-Franch F, Pavan MG, Jaramillo O, Palomeque FS, et al. (2013). Rhodnius barretti, a new species of Triatominae (Hemiptera: Reduviidae) from western Amazonia. Mem. Inst. Oswaldo Cruz 108 (Suppl 1): 92-99.

Alevi KC, Mendonca PP, Pereira NP, Rosa JA, et al. (2012a). Karyotype of Triatoma melanocephala Neiva and Pinto 
(1923). Does this species fit in the Brasiliensis subcomplex? Infect. Genet. Evol. 12: 1652-1653.

Alevi KC, Mendonca PP, Succi M, Pereira NP, et al. (2012b). Karyotype and spermatogenesis in Triatoma lenti (Hemiptera: Triatominae), a potential Chagas vector. Genet. Mol. Res. 11: 4278-4284.

Alevi KC, Mendonca PP, Pereira NP, Guerra AL, et al. (2013a). Distribution of constitutive heterochromatin in two species of triatomines: Triatoma lenti Sherlock and Serafim (1967) and Triatoma sherlocki Papa, Jurberg, Carcavallo, Cerqueira \& Barata (2002). Infect. Genet. Evol. 13: 301-303.

Alevi KC, Mendonça PP, Pereira NP, Rosa JA, et al. (2013b). Spermatogenesis in Triatoma melanocephala (Hemiptera: Triatominae). Genet. Mol. Res. 12: 4944-4947.

Alevi KC, Mendonca PP, Pereira NP, Fernandes AL, et al. (2013c). Analysis of spermiogenesis like a tool in the study of the triatomines of the Brasiliensis subcomplex. C R Biol. 336: 46-50.

Alevi KC, Rosa JA and Azeredo Oliveira MTV (2013d). Mini review: Karyotypic survey in Triatominae subfamily (Hemiptera, Heteroptera). Entomol. Ornithol. Herpetol. 2: 106.

Alevi KC, Mendonça PP, Pereira NP and Rosa JA (2014). Heteropyknotic filament in spermatids of Triatoma melanocephala and T. vitticeps (Hemiptera, Triatominae). Inv. Rep. Dev. 58: 9-12.

Barth R (1956). Estudos anatômicos e histológicos sôbre a subfamília Triatominae (Heteroptera, Reduviidae). VI parte: Estudo comparativo sôbre a espermiocitogênese das espécies mais importantes. Mem. Inst. Oswaldo. Cruz. 54: 599616.

da Rosa JA, Rocha CS, Gardim S and Pinto MC (2012). Description of Rhodnius montenegrensis n. sp. (Hemiptera: Reduviidae: Triatominae) from the state of Rondônia. Brazil Zootaxa 3478: 62-76.

da Rosa JA, Mendonça VJ, Gardim S and Carvalho SB (2014). Study of the external female genitalia of 14 Rhodnius species (Hemiptera, Reduviidae, Triatominae) using scanning electron microscopy. Parasit. Vectors 7: 17.

De Vaio ES, Grucci B, Castagnino AM and Franca ME (1985). Meiotic differences between three triatomine species (Hemiptera: Reduviidae). Genetica 67: 185-191.

Dujardin JP, Schofield CJ and Panzera F (2002). Los Vectores de la Enfermedad de Chagas. Académie Royale des Sciences d'Outre-Mer, Brussels.

Galvão C, Carcavallo RU, Rocha DS and Jurberg J (2003). A checklist of the current valid species of the subfamily Triatominae Jeannel, 1919 (Hemiptera, Reduviidae) and their geographical distribution, with nomenclatural and taxonomic notes. Zootaxa 202: 1-36.

Jurberg J, Cunha V, Cailleaux S and Raigorodschi R (2013). Triatoma pintodiasi sp. nov. do subcomplexo T. rubrobaria (Hemiptera, Reduviidae, Triatominae). Rev. Pan. Amaz. Saúde 4: 43-56.

Koshy TK (1979). Chromosomes of Triatominae II: Karyotypes studies of five species in the genus Rhodnius (Hemiptera: reduviidae). Acta Cient. Venez. 30: 191-195.

Lent H and Wygodzinsky P (1979). Revision of the Triatominae (Hemiptera: Reduviidae) and their significance as vector of Chagas's disease. Bull. Am. Mus. Nat. Hist. 163: 123-520.

Meneguetti DU, Soares EB, Campaner M and Camargo LM (2014). First report of Rhodnius montenegrensis (Hemiptera: Reduviidae: Triatominae) infection by Trypanosoma rangeli. Rev. Soc. Bras. Med. Trop. 47: 374-376.

Monteiro FA, Wesson DM, Dotson EM, Schofield CJ, et al. (2000). Phylogeny and molecular taxonomy of the Rhodniini derived from mitochondrial and nuclear DNA sequences. Am. J. Trop. Med. Hyg. 62: 460-465.

Noireau F, Diosque P and Jansen AM (2009). Trypanosoma cruzi: adaptation to its vectors and its hosts. Vet. Res. 40: 26.

Panzera F, Pérez R, Hornos S, Panzera Y, et al. (1996). Chromosome numbers in the Triatominae (Hemiptera-Reduviidae): a review. Mem. Inst. Oswaldo Cruz 91: 515-518.

Panzera F, Scvortzoff E, Pérez R and Panzera Y (1998). Cytogenetics of Triatomines. In: Atlas of Chagas' Disease Vectors in the Americas (Carcavallo RU, Galíndez-Girón I, Jurberg J and Lent H, eds.). Editora Fiocruz, Rio de Janeiro, 621-664.

Panzera F, Pérez R, Panzera Y, Ferrandis I, et al. (2010). Cytogenetics and genome evolution in the subfamily Triatominae (Hemiptera, Reduviidae). Cytogenet. Genome Res. 128: 77-87.

Pérez R, Panzera Y, Scafiezzo S, Mazzella MC, et al. (1992). Cytogenetics as a tool for triatomine species distinction (Hemiptera-Reduviidae). Mem. Inst. Oswaldo Cruz 87: 353-361.

Pita S, Panzera F, Ferrandis I, Galvao C, et al. (2013). Chromosomal divergence and evolutionary inferences in Rhodniini based on the chromosomal location of ribosomal genes. Mem. Inst. Oswaldo Cruz 108.

Poinar Jr G (2013). Panstrongylus hispaniolae sp. n. (Hemiptera: Reduviidae: Triatominae), a new fossil triatomine in Dominican amber, with evidence of gut flagellates. Palaeodiver 6: 1-8.

Schofield CJ and Dujardin JP (1999). Theories on the evolution of Rhodnius. Acta Biol. 21: 183-197.

Schreiber G and Pellegrino J (1950). Eteropicnosi di autosomi come possibile meccanismo di speciazione. Sci. Genet. 3 : 215-226.

Tartarotti E, Azeredo-Oliveira MT and Ceron CR (2006). Phylogenetic approach to the study of triatomines (Triatominae, Heteroptera). Braz. J. Biol. 66: 703-708.

Ueshima N (1966). Cytotaxonomy of the Triatominae (Reduviidae: Hemiptera). Chromosoma 18: 97-122.

Genetics and Molecular Research 14 (1): 222-226 (2015)

CFUNPEC-RP www.funpecrp.com.br 